have to conduct a controlled trial to deduce that I have helped this man to retain what is left of his health. In any case it is untrue to say that properly controlled trials have never shown the value of hypnosis in treatment. The work of Dr Maher-Loughnan has proved the effectiveness of hypnosis in the treatment of asthma.

Lastly, Dr Kinnell states that natural childbirth patients in one study did not differ from untrained patients in estimates of pain intensity. I fail to see what this statement has to do with his thesis as natural childbirth can in no way be equated with hypnosis.

H K Gooding

Surbiton, Surrey KT6 5BH

SIR,-That curious hostility shown by some members of our profession towards hypnosis as a therapeutic tool received its most recent expression in the letter from Dr H G Kinnell (17 March, p 751). Whether he has himself any direct experience in the subject is unclear-at least, no spark of original thought was allowed to break through the solemn procession of old shibboleths derived from work having, presumably, "scientific value" (whatever that may mean).

This old, old route was once traversed by the BMA itself-but that was in the last century, and the overwhelming weight of evidence since that hypnosis offers a method of treatment both unique and effective is today generally accepted. The logical outcome has been a demand, rightly supported by you ( 7 October, p 978), for instruction and training which (pace Dr Kinnell) is simple, safe, and infinitely rewarding.

I have found (and I am in good company) that hypnosis has a strictly limited role to play in psychotherapy. But there are certain conditions where it is, in my view, the method of choice. The deconditioning of phobic states, some sexual difficulties, and abreactive relief all come to mind.

General practice offers, probably, the widest scope for the deployment of hypnotherapy. Many of the psychosomatic illnesses are particularly susceptible and I have seen excellent results in certain forms of asthma, essential hypertension, and some skin disorders. Again, midwifery with a hypnotically trained mother is a most rewarding experience.

I am only too well aware that the shortage of time poses problems for the busy GP and it cannot be denied that the induction of hypnosis, at least initially, requires an unhurried approach. Still, our dental colleagues seem to manage as they have been quick to realise the benefit to the conscious patient and, above all, children that this technique provides. I am doubtful if time could be better spent than in adding this method of treatment to our therapeutic skills.

Chale, Isle of Wight PO38 2HB

WYNFORD REES

\section{Restrictions on NHS prescribing in Australia}

SIR,-Dr Tony Smith's description of the Australian pharmaceutical benefits scheme in "Restrictions on NHS prescribing in Australia" (13 January, $p$ 99) is misleading in several details.

The primary aim of the pharmaceutical benefits scheme is not to keep down costs but to provide an extensive range of drugs and medicinal preparations on a subsidised basis to all persons being treated by a medical practitioner in Australia. Due regard is given to the quality of the drugs, comparative efficacy and toxicity, and continuity of supply. At the same time the Government does endeavour to achieve maximum value for the taxpayers' money spent under the scheme.

The availability of phenoxymethylpenicillin as a benefit item is not restricted to the prophylaxis of rheumatic fever. Phenoxymethylpenicillin may be prescribed for any appropriate disease or purpose. However, when prescribed for the prophylaxis of recurrent streptococcal infections (including rheumatic fever) larger quantities may be supplied as a benefit than for other purposes.

The Pharmaceutical Benefits Advisory Committee, which recommends the drugs to be available as benefits, bases its deliberations primarily on medical considerations. The committee, when assessing drugs of comparable efficacy and toxicity, may take cognisance of price; but where price is considered it is merely as a secondary consideration.

The committee does not publish the Australian Prescriber, which is an independently edited publication financed by the Commonwealth Department of Health.

\section{Therapeutics Division,}

Department of Health, Woden, Canberra, ACT 2606,
Australia

SIR,-I refer to the article "Restrictions on NHS prescribing in Australia" (13 January, p 99), in which you refer to Australian Prescriber as being published by the Pharmaceutical Benefits Advisory Committee.

The journal is in fact independently edited, and it is the executive editorial board which commissions and approves all material that appears in the journal. Members of the board are chosen for their particular expertise and interest in therapeutic education at the practice level, one member being a general practitioner. Although the journal is financed by the Commonwealth Department of Health and the board is chaired by an officer of the Department, the senior adviser in clinical pharmacology, the board is genuinely independent of the Department and must continue to be so if the journal is to be accepted by the medical profession. An advisory editorial panel also provides an avenue by which the comments, views, and suggestions of all specialist colleges and societies, which are represented on the panel, can reach the executive editorial board.

\section{R C Hall}

Australian Prescriber,
Woden, Canberra, ACT 2606, Australia

\section{Detecting and managing hypertension}

SIR, - I read with great interest the paper by Dr D G Beevers and others (17 March, p 715) on the detection and management of hypertension. I was somewhat dismayed to find that there was a difference in the wording used in question 5 of the questionnaire and in the legend to table II. The former read "At what level of diastolic blood pressure would you begin to treat an asymptomatic 50-year-old man for hypertension ?" The latter states "Levels ... at which clinicians said they would begin drug treatment." I am sure that the authors do not regard "treatment" and "drug treatment" as synonymous.

In this context it is difficult to better a recent commentary by Ball1: "A mild hypertensive who stops smoking, reduces dietary fats and total calories, cuts down his salt intake and takes regular physical exercise is likely to improve his outlook much more than if he merely takes a drug to lower his blood pressure. He will certainly feel much better and avoid any side effects. These measures often lead to a fall in blood pressure and the need for drugs disappears."

I am sure that Dr Beevers and his colleagues need no conversion, but their article has important propaganda points to make for non-specialists in the field. If, as stated in their discussion, there is lack of evidence of benefit from "treatment" of mild hypertension then perhaps the method of treatment is wrong?

\section{B S SMITH}

Sandwell District Hospital, West Bromwich B71

${ }^{1}$ Ball, K P, Cardiovascular Forum, 1979, $1,7$.

\section{Neglected indexes}

SIR,-During the period between 6 January and 17 March of this year no mention is made in your book reviews of the indexes. On the assumption that your reviewers read the complete work from beginning to end and expect the same from their readers, why is the subject neglected? Furthermore the topic was not mentioned in any of the contributions based on the meeting of the Society of Medical Authors published on 3 February (p 309).

In this no-man's land between publishers and authors where each party often thinks the other should pay for the service, is this an expression of the frequently expressed view that indexes do not sell books?

A S THORLEY

Leatherhead, Surrey KT23 3HJ

\section{Action on alcohol}

SIR,-I have been catching up on some back numbers of the $B M f$ and wish to comment on your leader (10 February, $p$ 361) entitled "Action on alcohol."

Is it not time to admit that our whole approach to the problem of dangerous drugs is little short of insane? Alcohol is probably in truth far more dangerous a drug than heroin, possibly than any other drug of abuse. Apart from the appalling consequences to individual drinkers and the families of alcoholics, the social costs are almost beyond computation. Yet we allow advertising entirely freely. Even worse than the public commercial advertising is the implication which is so general in public entertainments, broadcast plays, and so on that drinking is a normal, acceptable part of life. We have even heard foolish suggestions that the increase of wine consumption in this country is to be approved despite the tragic experience in European countries. We ensure that most of our children will believe the drinking of alcohol to be a desirable part of maturity by tantalising them with alcohol, which is supposed to be kept just out of their reach until they are 18 . If our society really did care at all about the appalling damage done by alcohol and the anguish to so many individuals it would utterly prohibit all kinds of advertis- 